\title{
Discrepancies between immunological and caseinolytic plasma plasminogen assays in health and hyperfibrinolytic states
}

\author{
V. MUSUMECI, G. LEONE, AND B. BIZZI \\ From the Laboratory of Blood Coagulation, Department of Internal Medicine, the Catholic University, \\ Rome, Italy
}

SYNOPSIS A sensitive immunological assay for plasminogen and/or plasmin was developed by using a haemagglutination inhibition technique. Plasma and the corresponding euglobulin fraction of healthy subjects and of patients with hyperfibrinolysis (liver cirrhosis, thrombolytic treatment) were assayed for plasminogen using immunological and caseinolytic techniques. In hyperfibrinolytic states discrepancies were found between immunoreactive and caseinolytic plasma plasminogen whereas a good correlation was observed between immunoreactive and caseinolytic euglobulin plasminogen. Experiments in vitro suggested that these discrepancies might depend on the presence in hyperfibrinolytic plasma of variable amounts of plasmin(ogen)-related antigen which has no caseinolytic activity and is not precipitated with euglobulin.

Human plasmin and its proenzyme plasminogen can be measured by a variety of techniques. Methods dependent on the proteolytic activity of plasmin, obtained after urokinase or streptokinase activation of plasminogen, such as whole blood clot lysis, fibrin plates, or casein hydrolysis have been widely used.

The preparation of highly purified plasminogen and plasmin and the subsequent availability of specific antisera have in the last few years permitted the immunological approach to the plasminplasminogen assay. Various immunological methods have been developed such as electrophoresis in agarose gel containing antibodies (Ganrot and Niléhn, 1968; Nilsson and Hedner, 1971), radioimmune assay (Rabiner, Goldfine, Hart, Summaria, and Robbins, 1969), radial immunodiffusion on cellulose acetate strips (Mannucci, Stabilini, Bragotti, Marasini, and Agostoni, 1971), and recently haemagglutination inhibition techniques (Ludlam and Das, 1971; Wu, Jacobsen, and Hoak, 1973). The careful evaluation of these methods shows that the immunological assay of plasminogen is only weakly correlated with the proteolytic assay; a very poor or no correlation between the two methods was observed when investigations were carried out on plasma or

Received for publication 30 May 1974. serum of a large group of subjects in health and in various physiological or pathological conditions (Ganrot and Niléhn, 1968; Rabiner et al, 1969; Ludlam and Das, 1971; Mannucci et al, 1971).

The aim of this work was to investigate the correlation between the immunological and caseinolytic assays of plasminogen and the significance of possible discrepancies.

\section{Materials and Methods}

Plasma samples were obtained by centrifuging blood collected with $1 / 10$ volume of $3.8 \%$ sodium citrate at $2000 \mathrm{~g}$ for 30 minutes at $4^{\circ} \mathrm{C}$. Euglobulin fractions were prepared by a modification of the technique of Chakrabarti, Bielawiec, Evans, and Fearnley (1968). Standard reference plasmas or euglobulin were prepared from a pool of 10 healthy donors. The caseinolytic assay was performed on euglobulin according to the technique of Johnson, Kline, and Alkjaersig (1969). Activator was measured by a modified plasminogen-rich agarose fibrin plate method (Walton, 1966).

The plasminogen immunoassay was performed by using a haemagglutination inhibition technique similar in details to that described by Merskey, Lalezari, and Johnson (1969) for measuring fibrinolytic split products. Hüman red blood cells group $\mathbf{O}$ 
were used. After washing and tanning the red cells were coated with plasminogen (plasminogen, grade A, AB Kabi, Stockholm, Sweden) by adding to a $2 \%$ red cell suspension an equal volume of plasminogen solution $(20 \mu \mathrm{g} / \mathrm{ml})$. The mixture was incubated for one hour at room temperature. After repeated washing a $4 \%$ red cell suspension was prepared and used in the assay. Plasminogen antiserum obtained from Behring-werke AG, MarburgLahn, Germany was currently used in a $1 / 1000$ dilution. The inhibition assay was performed on microplates. The samples were serially diluted $1 / 9$, $1 / 12,1 / 18$, etc, with citrate buffer containing $1 \%$ of rabbit serum, and $0.05 \mathrm{ml}$ of diluted antiserum was added to each microplate well containing $0.05 \mathrm{ml}$ of diluted sample, and, after incubation of the plate at $4^{\circ} \mathrm{C}$ for 30 minutes, $0.02 \mathrm{ml}$ of plasminogen-coated red cells was added to the mixtures. The plate was then left for one hour at room temperature before reading the extent of agglutination. The maximum dilution of sample which inhibited haemagglutination was recorded. The plasminogen concentration was expressed in a percentage relative to that of the reference pool of euglobulin simultaneously assayed.

\section{Results}

SENSITIVITY OF THE IMMUNOLOGICAL ASSAY A sample of pooled euglobulin from normal subjects containing 3.4 caseinolytic units plasminogen $/ \mathrm{ml}$ was examined by the haemagglutination inhibition method and was shown to produce as a rule a titre of approximately 288 . It was concluded from these data that approximately 0.011 caseinolytic units plasminogen $/ \mathrm{ml}$ neutralized the antiserum present in each assay well and inhibited red cell agglutination. Thus the sensitivity of our assay was about 0.011 caseinolytic units plasminogen $/ \mathrm{ml}$ of sample.

\section{CORRELATION BETWEEN IMMUNOLOGICAL}

AND CASEINOLYTIC ASSAYS IN HEALTHY

SUBJECTS

The plasminogen concentration in plasma and euglobulin of the same plasma obtained from normal subjects was determined immunologically and as caseinolytic activity. A fairly good correlation between immunological and caseinolytic methods was observed when plasminogen immunoassay was carried on euglobulin ( $r=0.89 ; P=<0.001)$. On the other hand, plasma plasminogen immunoassay showed a less significant correlation with the caseinolytic assay $(r=0.53 ; P=>0.01)$. However, the correlation between the two methods became highly significant when the samples with low caseinolytic activity were eliminated from the statistical computation ( $\mathrm{r}=0.67 ; \mathrm{P}=<0.01$ ) (fig. 1).

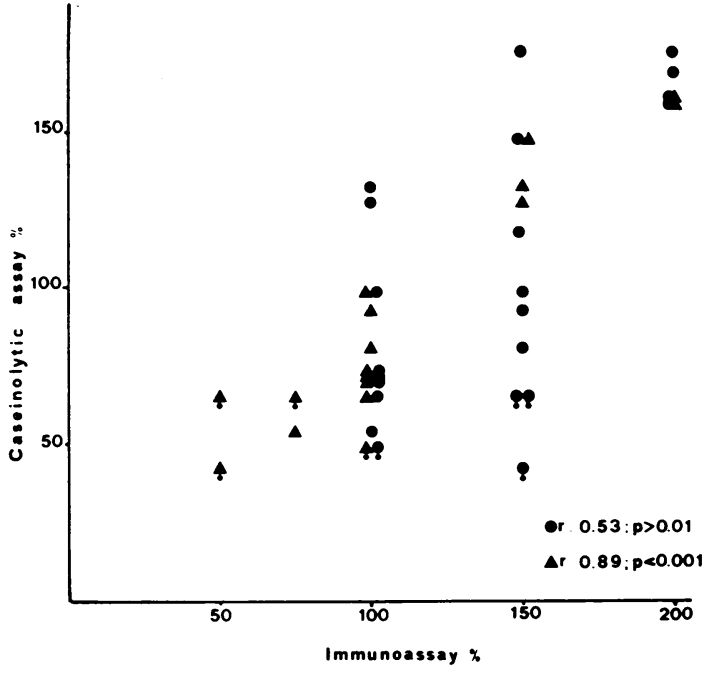

Fig 1 Correlation between plasminogen values obtained by caseinolytic assay and plasma (O) or euglobulin ( $\mathbf{( \Delta )}$ immunoassay in healthy subjects.

(?.) Samples left to stand at room temperature before assay.

Verifying the procedure for assays, it was realized that the samples showing low caseinolytic activity had accidentally been allowed to stand for some time at room temperature before being tested. This fact suggested that the discrepancies between plasma plasminogen immunoassay and caseinolytic assay could be due to the plasminogen activation occurring spontaneously in vitro in the samples which were not immediately tested.

\section{EXPERIMENTS in vitro}

In order to investigate the influence of plasminogen activation on the plasminogen immunoassay performed in plasma or euglobulin, urokinase was added at increasing concentrations to plasma samples obtained from a normal subject. The samples were then incubated for 20 minutes at $37^{\circ} \mathrm{C}$. After withdrawing the plasma to be used for caseinolytic assay, plasminogen activation was stopped in all samples by adding EACA $\left(10^{-2} \mathrm{M}\right)$. In previous experiments it was shown that this concentration of EACA did not influence the haemagglutination inhibition technique.

Plasminogen immunoassay was then performed on plasma, euglobulin, and the supernatant after euglobulin precipitation. A caseinolytic assay was performed on the euglobulin and supernatant after euglobulin precipitation. The mean results of four experiments are summarized in the table. The level of immunoreactive plasminogen of plasma was 


\begin{tabular}{|c|c|c|c|c|c|}
\hline \multirow[t]{2}{*}{ Urokinase (units/ml) } & \multicolumn{3}{|c|}{ Immunological Method } & \multicolumn{2}{|c|}{ Caseinolytic Method (caseinolytic units/ml) } \\
\hline & Plasma (\%) & Euglobulin (\%) & $\begin{array}{l}\text { Supernatant o } \\
\text { Euglobulin }(\%)\end{array}$ & Euglobulin (\%) & $\begin{array}{l}\text { Supernatant of } \\
\text { Euglobulin }\end{array}$ \\
\hline $\begin{array}{r}0 \\
100 \\
250 \\
500 \\
1000\end{array}$ & $\begin{array}{l}106(75-150) \\
112(100-150) \\
150(150-300) \\
200(150-300) \\
270(200-400)\end{array}$ & $\begin{array}{r}100(75-150) \\
93(75-100) \\
75(50-100) \\
38(25-50) \\
18(12-25)\end{array}$ & $\begin{array}{r}4(1-6) \\
7(6-12) \\
40(25-50) \\
93(50-150) \\
210(150-300)\end{array}$ & $\begin{array}{r}107 \\
89 \\
62 \\
27 \\
11\end{array}$ & $\begin{array}{l}0 \\
0 \\
0 \\
0 \\
0\end{array}$ \\
\hline
\end{tabular}

Table Plasminogen assay

shown to increase by increasing the urokinase concentration. Only a part of the whole immunoreactive plasmin(ogen)-like material present in plasma was found in the euglobulin precipitate and was shown to be caseinolytic. No caseinolytic activity was found in the supernatant of euglobulin where the immunoreactive plasmin(ogen)-like material not precipitable with euglobulin was recovered. These data indicated that a variable amount of inactive plasmin(ogen)related antigen which was not precipitated with euglobulin might be present in plasma samples where plasminogen activation has occurred.

\section{CORRELATION BETWEEN IMMUNOLOGICAL}

\section{AND CASEINOLYTIC ASSAYS IN}

HYPERFIBRINOLYTIC STATES

In subsequent work particular care was taken in storing samples at low temperature before assay. Moreover, when high fibrinolytic activity was suspected the samples to be examined by immunoassay were collected with the addition of $10^{-2} \mathrm{M}$ EACA

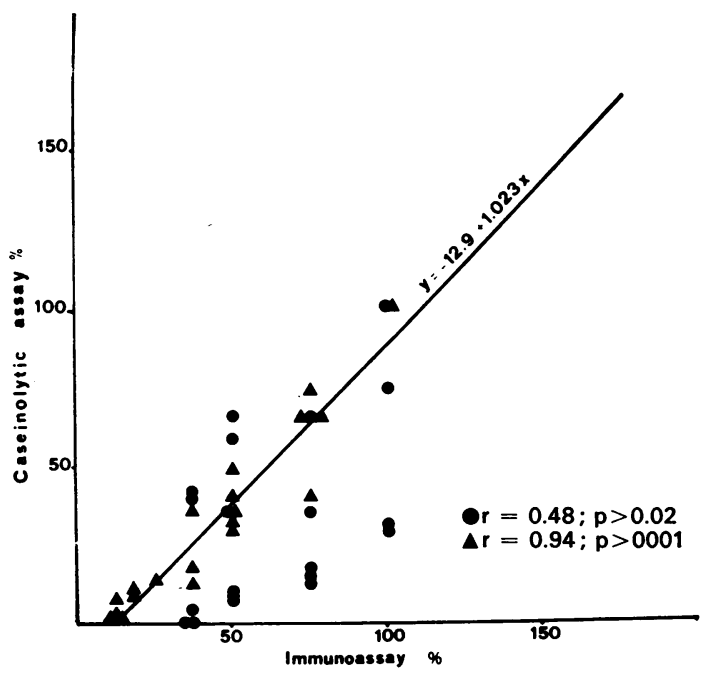

Fig 2 Correlation between plasminogen values obtained by caseinolytic assay and plasma (O) or euglobulin ( $(\Delta)$ immunoassay in subjects with high fibrinolytic activity. in order to prevent plasminogen activation in vitro. Samples obtained from subjects with presumably high fibrinolytic activity (liver cirrhosis, thrombolytic treatment) were examined by the immunoassay performed on plasma and euglobulin and by the caseinolytic assay. The same samples were also examined for activator activity by the plasminogenrich agarose fibrin plate method. Again a good correlation was observed between euglobulin plasminogen immunoassay and caseinolytic assay $(r=0.94$; $\mathbf{P}<0.001$ ), whereas only a slight correlation was found when immunoassay was performed on plasma $(r=0.48 ; P>0.02)$. The regression line calculated for immunoreactive and caseinolytic euglobulin plasminogen intersected the immunoreactive axis suggesting an overestimation of the immunological method by about $10 \%$ (fig 2 ).

In fig 3 the activator activity of each sample is plotted against the difference observed in the same sample between plasma and euglobulin immunoassays. This difference, as was shown in previous

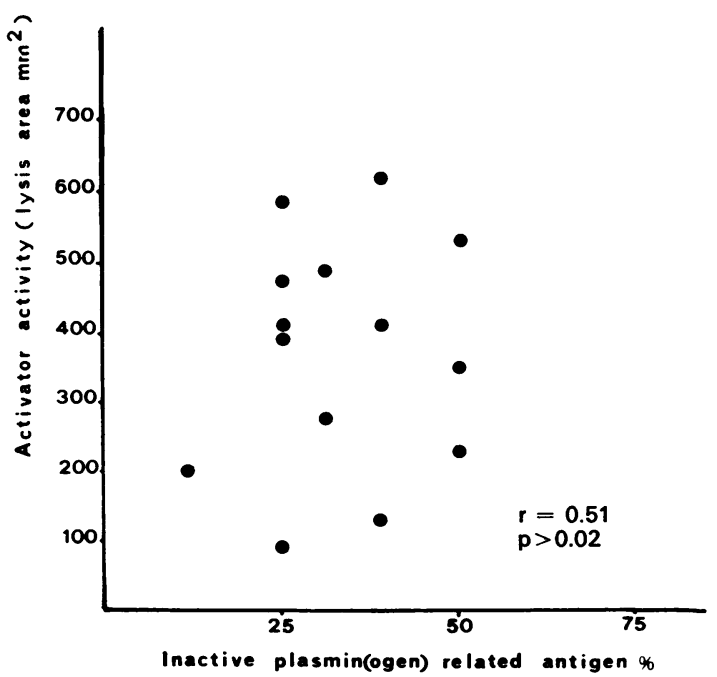

Fig 3 Correlation between activator activity and inactive plasmin(ogen)-related antigen in subjects with high fibrinolytic activity. 
experiments in vitro, should represent the amount of inactive plasmin(ogen)-related antigen. Only a slight correlation was observed $(\mathrm{r}=0.51 ; \mathrm{P}>0.02)$.

\section{Discussion}

The poor correlation between immunological and caseinolytic assays of plasminogen observed by various authors (Ganrot and Niléhn, 1968; Rabiner et al, 1969; Ludlam and Das, 1971; Mannucci et al, 1971) has been related to different factors. According to Ludlam and Das (1971), the discrepancies between immunological and caseinolytic assays could be due to the presence in plasma of a heterophile antibody which might interfere with the agglutination inhibition of the sheep red cells used in their test. Others (Ganrot and Niléhn, 1968; Rabiner et al, 1969) have observed that the immunological assay gave an overestimation of plasminogen concentration in comparison with the caseinolytic technique and ascribed this fact to the incomplete removal of antiplasmin or activator inhibitor by the relative steps of the caseinolytic technique.

In our assay the problem of heterophile antibody was overcome by using human red cells. Our results showed that in normal subjects plasma immunoassay could well be correlated with caseinolytic assay provided that special precautions were undertaken in order to prevent spontaneous plasminogen activation in vitro. A weak correlation was, however, observed when plasma immunoassay was performed in subjects with high activator activity. In all cases the immunoassay performed on euglobulin showed a highly significant correlation with the caseinolytic assay although the regression line gave an overestimation of about $10 \%$ by the immunological method. This overestimation could be due either to the greatest sensitivity of the immunological method or to the incomplete removal of inhibitors by the caseinolytic technique. Our experiments in vitro suggested that the discrepancies between immunological and caseinolytic assay might depend on the presence in hyperfibrinolytic plasma of variable amount of plasmin(ogen)-related antigen which has no caseinolytic activity and is not precipitated with euglobulin. The increase in immunological concentration of plasminogen in urokinase-treated plasma might be due to an increase in the immunological reactivity of plasminogen caused by the activation process.

A variable amount of inactive plasmin(ogen)related antigen was found in plasma of subjects with high activator activity. It could be suggested that this material represents plasmin(ogen) degradation products or antiplasmin-bound plasmin. Immunoelectrophoretic analysis has shown that a plasminrelated antigen was complexed to $\alpha_{2}$ macroglobulin in urokinase-treated plasma (Harpel and Mosesson, 1973).

The fact that only a weak correlation was found in vivo between activator activity and inactive plasmin(ogen)-related antigen could be explained by the occurrence of a clearance mechanism. In conclusion, the plasminogen immunoassay by the haemagglutination inhibition technique could be a sensitive indicator of caseinolytic plasminogen when it is performed on euglobulin. In addition the discrepancies between plasma and euglobulin immunoassay might provide information on the level of inactive plasmin(ogen) products present in blood in hyperfibrinolytic states.

\section{References}

Chakrabarti, R., Bielawiec, M., Evans, J. F., and Fearnley, G. R. (1968). Methodological study and a recommended technique for determining the euglobulin lysis time. J. clin. Path., 21 698-701.

Ganrot, P. O., and Niléhn, J. E. (1968), Immunochemical determination of human plasminogen. Clin. chim. Acta., 22, 335-340.

Harpel, P. C., and Mosesson, M. W. (1973). Degradation of human fibrinogen by plasma $a_{2}$ macroglobulin enzyme complexes. J. clin. Invest., 52, 2175-2184.

Johnson, A. J., Kline, D. L., and Alkjaersig, N. (1969). Assay methods and standard preparations for plasmin, plasminogen and urokinase in purified systems. Thrombos. Diathes. haemorrh. (Stuttg.), 21, 259-272.

Ludlam, C. A., and Das, P. C. (1971). Plasminogen assay by a haemagglutination inhibition technique. J. clin. Path., 24, 136-142.

Mannucci, |P., | Stabilini, R., Bragotti, R., Marasini, B. and Agostoni, A. (1971). Enzymatic and immunochemical determination of plasminogen and plasmin in different physiological and pathological states. J. clin. Path., 24, 228-233.

Merskey, C., Lalezari, P., and Johnson, A. J. (1969). A rapid simple sensitive method for measuring fibrinolytic split products in human serum. Proc. Soc. exp. Biol. (N.Y.), 131, 871-875.

Nilsson, I. M., and Hedner, U. (1971). Immunochemical plasminogen assay. Thrombos. Diathes. haemorrh. (Stuttg.), Suppl. 45, 387 . 388.

Rabiner, S. F., Golfine. I. D., Hart, A., Summaria, L., and Robbins, K. C. (1969). Radioimmunoassay of human plasminogen and plasmin. J. Lab. clin. Med., 74, 265-273.

Walton, P. L. (1966). An improved fibrin plate method for the assay of plasminogen activators. Clin. chim. Acta., 13, 680-684.

Wu, K. K., Jacobsen, C. D., and Hoak, J. C. (1973). Highly sensitive method for the assay of plasminogen. J. Lab. clin. Med., 81, 484-488. 